\title{
Rituals at Table: An Interpretation of Dietary Rituals in Contemporary Japan
}

\author{
Jiaxuan Li
}

\author{
Xi'an Gaoxin NO.1 High School \\ $X i^{\prime}$ an, 710000, China \\ 2329195177@qq.com
}

\begin{abstract}
This paper mainly discusses the manifestation and influence of pre-meal ritual and drinking culture in Japan. Using the chronological description method, by taking examples and querying the past historical data, it is aimed to restore the most authentic Japanese pre-meal ritual. Its purpose is to take the in-depth discussion of non-religious culture as the breakthrough and dining as the research object. Through the discussion of the historical development and the author's personal experience, the research reflects that the Japanese society is with high rank and low order, paying great attention to etiquette. It is also hoped that relevant researches can draw conclusions by various methods in the future and lay a foundation for related topics in this field.
\end{abstract}

Keywords: Ritual, Performance, Japan, Pre-meal, Itadakimasu, panocipticon

\section{INTRODUCTION}

Existing literature mainly discusses dietary rituals related to religion, such as Christians' saying grace before meals for thanking God for the food while praying [1]. Correspondingly, Jews also say pre-meal prayers, though they only acknowledge the Old Testament. Similarly, diet is also seen as an important way of practicing Buddhism by Buddhists, who must chant mantras and sutras together before breakfast and lunch every day and offer a small amount of food to Buddha before eating [2]. The same custom also exists among Islamist, who pray after preparing and eating beef, to thank Allah for the gift and eliminate the sin of killing living creatures [3]. It can be seen that nearly all religions in the world have their prescribed pre-meal rituals and dietary taboos. However, there are few records on pre-meal dietary customs and rituals of East Asian countries. Though no religion was developed locally, the age-old dietary culture has evidently become customs followed by local people. Japan has the most representative dietary culture and rituals. Japanese pre-meal culture and drinking culture have gradually discarded previous tedious procedures, and formed a set of plain and simple dietary customs. This is not only aimed to save food and protect the environment, but also helpful to the harmonious and orderly development of interpersonal relationships. This paper mainly studies the influence and performance of the pre-meal ritual in contemporary Japan. Through the record of the historical evolution and development of pre-meal ritual, the cultural style of Japanese society is restored to the greatest extent. The research goal of this paper is thus to reflect the real Japanese society and its culture through the study of Japanese eating rituals, which is of great help to the further study of Japanese history and traditional customs.

\section{ANALYSIS}

\subsection{Pre-meal ritual as a performance in Japanese society}

In Japanese culture, pre-meal dietary rituals such as Itadakimasu should be interpreted as a performance. As defined in anthropology, performances are no longer major imitations or dramas, but an active mode of applying multiple necessary elements and inherent elements in the constantly changing fields of the performance analysis framework in dramatic performances of social life [4]. From another perspective, we can see that Japanese dietary culture is a kind of ritual performances in nature. For example, the Japanese say "Itadakimasu" before meals, to express their gratitude for accepting food. Itadakimasu is a very polite and respectful expression, which is related to a 
traditional way of gratitude, that is, raising food received overhead. Before starting to eat, a family will say it repeatedly [5].

About its origin, experts hold different opinions. A relatively unified explanation is that a thought on abstinence generated in the Kamakura Period resulted in indifference of many samurai to diet. It took a long time for the Japanese to get out of the deep-rooted culture, but they still cannot fully get rid of its profound influence. Not until the emergence of set meals did many Japanese start cherishing food and enjoying the spiritual enjoyment brought by food. Over time, they even find "gourmet food cannot compare with beautiful utensils", and enjoy the wonderful feel of placing exquisite utensils on the table [6].

For the Japanese, homes are their private spaces, where they are more unwilling to be disturbed and only invite those they really value. The author was honored to be invited to a friend's home and gained a deep experience of the fun of a Japanese dinner. Before dinner, everyone said, "Thank you for your hospitality, and I will start eating." Only after elders of a family took their food could children start eating. Each dish was small but gave full play to the original taste of food as much as possible, with delicate seasoning and utensils that could reflect the charm of food. Meanwhile, the seasonal design of dishes showed how much effort the host put into cooking. The host's elaborate preparation and hospitality to a guest fully demonstrated their cultural identity of respecting elders and having gratitude for food and nature. They hoped that the foreign guest could also experience the ritual and atmosphere. This not only shows sincerity and kindness of the Japanese to their friends, but also epitomizes the Japanese society through table manners and the pre-meal ritual.

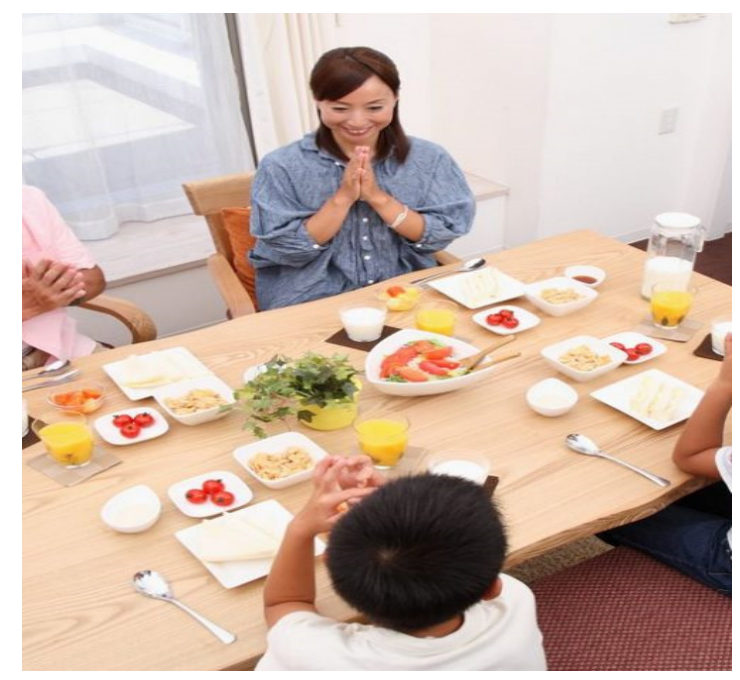

Figure 1 Caption of Japanese people before the meal (Source: Coto Academy)[13].

\subsection{A unique Japanese drinking culture}

In Japan, changes in drinking rituals well reflect the trend of Japanese classes from loosening to solidification. In Japanese society, after the Kamakura Period, a drinking ritual would be held to pray for victory on heading to a battlefield. First, a drinking ritual named "Shikisangon", which is a dietary form of setting 2 to 6 dishes centering on ritual rules. In the development of "Shikisangon", there are different rules for the shape and quantity of dishes, sizes of utensils, and matching of utensils with food. Generally speaking, a soup bowl and a rice bowl with only side dishes (mixed shredded raw fish or sashimi with vinegar) are first served. Second, wine is poured in cups, and then a bowled dish, a roasted dish and a boiled dish are served. These are the soup and three dishes at the beginning of a banquet. Afterwards, the host pours a cup of wine for each guest in turn while dividing dishes, and then each guest drinks a toast to the host. Last, rice and soup are removed, and pickles are served to finish the banquet [7]. In the Edo Period, izakayas were truly developed. At that time, many pubs would provide drinks and side dishes, and such places were called "ituzuke te nomu", which literally means "stop to have a drink". In the 1970s, the Japanese economy entered a golden age, when well-off Japanese, especially office workers, liked having a drink with friends or talking business with customers while drinking; since the 1980s, izakayas have further developed into chain restaurants, not only with a greater variety of drinks and dishes but also at an increasingly affordable price.

As the Japanese attach great importance to interpersonal relationships, a newcomer to a company must dine together with colleagues. In most cases, newcomers have to treat others, or else they will be regarded as asocial. Different from the gathering of relatives and friends, everyone can eat, drink and enjoy freely here. When dining together with superiors or colleagues, one usually has to reach the designated place about 10 minutes earlier, for it is not good to arrive too early or too late. When all people arrive, the Japanese will have a toast together, and show their sincerity by drinking up the first cup [8]. However, if there is a senior or a superior of a company, he should be treated first. Usually, juniors will fill the wine cups of seniors, and put their cups lower than those of seniors to show respect when clinking cups. One may not drink and eat every time, but he or she should take part in most circumstances. This shows that in Japanese culture, drinking ceremony strengthens the expression of "order and control". In essence, it is to control human behavior with a hierarchy [9]. Such a disciplinary technique is very elaborate and infiltrated into every detail of the society, along with the emergence of a whole set of hierarchical monitoring. This is just like imprisoning people at the lowest stratum of society in a 
"panocipticon", which is composed of a watchtower with windows in all directions in the center surrounded by a circular building; with a backlight effect, activities of prisoners in prison cells can be clearly seen by surveillants, while the imprisoned do not know whether they are monitored. The result of such hierarchical monitoring is that the imprisoned will enter a conscious spontaneous state, which ensures they play the role that they should play automatically. Satirically, it was just in these details of control that humans in a modern humanitarian sense emerged [10].

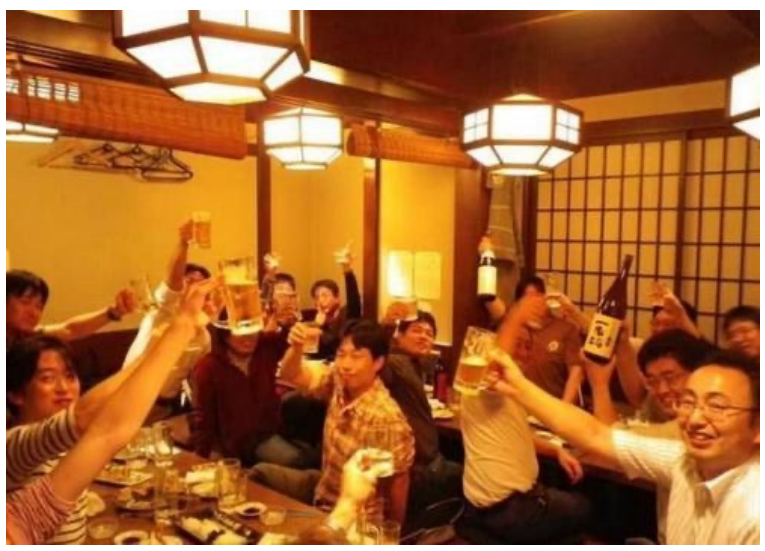

Figure 2 Toaste of Japanese people in a bar/restaurant (Source: Baidu library)[14].

\subsection{Changes in Eating rituals in Japan during the pandemic}

The outbreak of COVID-19 in 2020 has hindered the development of the Japanese catering industry and forced the economy to decline rapidly. The changes brought were all-around, and the dining patterns have become different from previous ones. Food and beverage outlets for a single person have been closed one after another, and gatherings for dining and drinking are prohibited as well. While the outside world was worried that the pandemic would further stress people out, there came unexpected news from Japan: the suicide rate in Japan in April 2020 fell by 20\% compared with the same period last year. Relevant experts said that it may be related to school closures and staff working from home during the pandemic. The pandemic has brought work and life together and integrated numerous Japanese dining rituals. For example, the Japanese drinking culture is integrated into family meals. The drinking culture started to return to its purest form without the restraint between the superior and the subordinate or the deliberate maintenance of social relationships. In fact, drinking with family members is never a habit in Japanese families. However, the elders in the family will have a drink after dinner and chat about their thoughts or ordinary trivial matters with the rest members because of the pandemic. Such a drinking culture without social characteristics because of the pandemic is a unique dining ritual in itself-purely serving food to the heart. Family members have the opportunity to promote their relationships and they thus become more harmonious. "The decrease in suicide rate may be largely related to lower social and learning pressure," said the former counselor of the Japan Lifeline Alliance.

The Japanese not only have to change the way of dining together during the pandemic but also need to bear the risks brought about by travel. As is well-known, the sakura is in full bloom in the middle of summer, which will last for only one week. Many Japanese people invariably put down their work and go on picnics in the suburbs with their families during this period. The sakura represents the Japanese spirit of very moment as its flowering period is quite short and will not appear frequently throughout the year. Therefore, every Japanese will go to this beautiful invitation of nature. On the one hand, people can enjoy the splendid sakura, on the other hand, they can commemorate the hard-won leisure time with their families. Such a habit was gradually accepted by every Japanese and eventually became a ritual. However, many Japanese could not go out to enjoy the sakura or even reunite with their families due to the pandemic. It is worth noting that this habit of the Japanese has not been affected by the impact of the pandemic. In April, when the epidemic situation became increasingly serious and the Japanese government ordered the closure of most schools in Japan, many Japanese still took their children to hold the "entrance ceremony" under sakura trees. Although family members were not able to sit under a tree and have fun talking and savoring food, the Japanese believed that holding a solemn entrance ceremony for their children is an important part of their lives. Such a ceremony is indispensable and receiving blessings from family members under the sakura tree is considered by the Japanese to be the happiest moment in their lives.

\section{CONCLUSIONS}

The study of pre-meal and drinking rituals in Japan shows that the Japanese society is strictly hierarchical. Meanwhile, it also reveals respect for seniority and politeness in the Japanese society. These two rituals are both helpful to our exploration of an underlying Japanese social network built based on etiquette. In workplaces, one should show absolute respect and humble reverence for leaders. Even two people of the same social status show different degrees of respect on different occasions. When they both dressed casually, they do not need to bow to each other, but if one of them wears a military uniform, the other will have to bow to him. At home, people also have to learn and follow manners cautiously. It means that the one saluting the other knows the right and power of the latter, and the other saluted also realizes that he should shoulder corresponding duties at the position. 
However, there are also disparities between the two rituals. The simple pre-meal ritual shows respect for food and gratitude for the gift of nature. In some sense, it promotes more harmonious interpersonal communication by praising the host's cooking skills. In contrast, the modern Japanese drinking ritual, including the drinking culture derived, is filled with top-down social oppression in the hierarchy. Though such discomfort can be counteracted by some factors in specific circumstances, respect for the privilege class is not discarded but inherited all the way. Currently, the overall cultural landscape of the Japanese society cannot be represented simply in these two aspects. Further research is needed in this field to study the deeper hierarchical culture of Japan. It may be more helpful to study this in different fields, such as art and religion.

Japanese rituals before meals reflect the basic state of mutual respect in Japanese society. At the same time, Japanese wine culture reflects the social characteristics of rigid class and orderly age in Japan.

This article mainly carries a thorough analysis to the Japanese pre-meal ritual, and reflects the contemporary Japanese society basic level life present situation and the spiritual core, it has the great reference value to the later researchers.

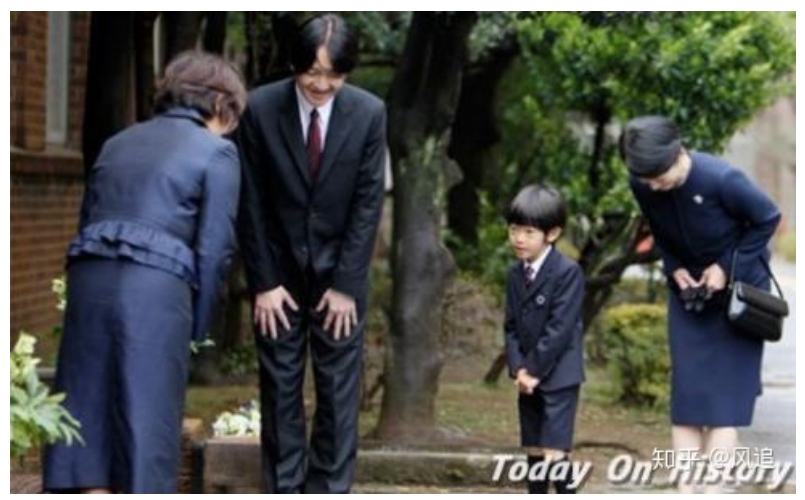

Figure 3 Japanese bow to each other (Source: Baidu Library)[15].

\section{ACKNOWLEDGMENTS}

At the end of this article, I would like to thank Ziru, my teacher, for giving me inspiration and ideas for writing. Secondly, I would like to thank my professor Stephen for his academic correction and guidance. I also want to thank my mother, who supported me to finish the whole paper writing and always comforted me when I wanted to give up.

\section{REFERENCES}

[1] Yu Long. Christian Dietary Culture [J]. Agriculture Engineering Technology. Green Food, 2005, 03:41.

[2] Ma Guibao. Analysis of Islamic Dietary Culture [J]. China Muslim, 2007, 02:13-15.
[3] Chen Xingqiao. Buddhism and Chinese Dietary Culture [J]. Fa Yin, 1997, 01:6-10.

[4] Performance Studies, D. Soyini Madison, 26 AUGUST 2013, https://www.oxfordbibliographies.com/view/docum ent/obo-9780199766567/obo-9780199766567-0119 .xml.

[5] What do Itadakimasu and Gouchisousamadesu mean? Coto Japanese Academy, JULY 2016, https://cotoacademy.com/itadakimasu-and-gochiso usamadesu/

[6] Longyuan Journal, http://www.qikan.com.cn.

[7] Analysis of Japanese Dietary Culture, Zhao Hongtao,

[8] Course Education Research Issue 12, 2016.

[9] Japanese Dietary Culture-The Inheritance of Japanese Food and Food Education.

[10] Haruyama Yukio: Cultural History of Beer $<1>$, Heibonshiya, June 1990.

[11] Noritake Kanzaki: Japanese Culture of Wine Stories about Wine You Want to Know, Kadokawa Library, September 2006.

[12] Michel Foucault: Discipline and Punish: The Birth of the Prison, 1977.

[13] https://www.sohu.com/a/276431185_287945.

[14] http://www.lvmama.com/trip/show/322350.

[15] https://www.163.com/dy/article/EAI2QH0T05371N R8.html. 